\title{
Clinical Significance of Incision Location on Guided Bone Regeneration: Human Study
}

\author{
Sang-Hoon Park* and Hom-Lay Wang ${ }^{\dagger}$
}

Background: Membrane exposure has been associated with poor clinical outcomes in guided bone regeneration. This prospective human study examined the effect of incision locations on flap survival and membrane exposure.

Methods: Twenty-nine implant-associated buccal dehiscence defects in 25 patients were augmented using particulate mineralized human allograft. Ten sites received a collagen bioabsorbable membrane, 10 sites received acellular dermal matrix, and nine sites were treated with bone graft alone. All implants achieved primary stability and passive flap tension at the time of flap closure. Incision location was measured as the distance from the initial incision line to the mucogingival junction. The same measurements were made at 2 weeks and 1 month to represent the length of the flap that survived. The length of the flap that survived at 2 weeks was compared to the mean width of buccal keratinized gingiva (KG) of adjacent teeth. Other clinical parameters recorded included incidence of early membrane exposure and gingival thickness at midcrest and $6 \mathrm{~mm}$ buccal and lingual to the mid-crest at baseline.

Results: At 2 weeks, 10 sites experienced early exposure. Exposed sites that were not covered by 1 month remained exposed. Membrane-treated groups showed no significant difference between the width of adjacent buccal KG and the length of the flap that survived at 2 weeks. The length of the flap that survived beyond the mean width of adjacent KG was significantly greater for the graft alone group $(1.6 \pm 0.4 \mathrm{~mm} ; P=0.002)$. When the gingival thicknesses of exposed and non-exposed cases were compared, only palatal/lingual gingival thickness showed a significant difference $(P=0.002)$.

Conclusions: Within the limits of the study, it was concluded that the location of the crestal incision might be a significant factor in reducing the incidence of membrane exposure by minimizing flap necrosis. The mean KG width of adjacent teeth may be used as a guide to determine the initial incision location. However, this effect may be less significant in palatal/lingual gingiva $>3.0 \mathrm{~mm}$. J Periodontol 2007;78:47-51.

\section{KEY WORDS}

Bone; bone regeneration; dental implants; grafts; membranes.

\footnotetext{
* Currently, Department of Periodontology, University of Maryland, Baltimore, MD; previously, Department of Periodontics and Oral Medicine, School of Dentistry, University of Michigan, Ann Arbor, MI.

$\dagger$ Department of Periodontics and Oral Medicine, School of Dentistry, University of Michigan.
}

$\mathrm{F}$ actors that have been suggested to influence the outcome of guided bone regeneration (GBR) include patient factors (e.g., smoking), ${ }^{1,2}$ excessive swelling, passive flap tension, cortical penetration, ${ }^{3}$ defect morphology, ${ }^{4-8}$ defect length and defect angle, ${ }^{5,6}$ membrane fixation, ${ }^{9}$ and materials used. Even with carefully selected cases, impaired soft tissue wound healing may occur, which often results in membrane exposure. The literature reported up to $60 \%$ of membrane exposure, and this significantly reduced the amount of bone regenerated by up to $81 \% .^{5,10-13}$ Infection and/or premature degradation of membrane were suggested as etiologic factors for compromised bone regeneration. Therefore, minimized wound opening becomes essential in any type of regenerative procedure.

Incision design has been suggested to influence surgical wound healing. ${ }^{14-19}$ Reports in the literature showed that the success rate of osseointegration is not dependent on incision design. ${ }^{14,15,20}$ Crestal bone loss also was similar among different types of incisions. ${ }^{21}$ However, histologic analysis in a dog model revealed that a paracrestal incision healed more slowly than a crestal incision because of disturbed wound healing, flap necrosis, and subsequent bone necrosis. ${ }^{16,17}$ Furthermore, although overall osseointegration remained unaffected, clinical human studies reported less edema, inflammation, and pain with a

doi: 10.1902/jop.2007.060125 
crestal incision compared to a vestibular or mucobuccal fold incision. ${ }^{14,15,18} \mathrm{~A}$ recent human cadaver study speculated that impaired wound healing in a paracrestal incision design might result from a compromised vascular network between primary buccal or lingual blood supply. ${ }^{21}$ This relatively avascular zone over the edentulous crest is $\sim 1$ to $2 \mathrm{~mm}$ wide. ${ }^{19}$ Therefore, a crestal incision within this zone may improve wound healing by maintaining the main blood supply to each flap. ${ }^{19}$ However, the location of the avascular zone may change within the crestal region as the edentulous ridge undergoes horizontal resorption. Subsequently, locating this avascular zone clinically may prove useful in minimizing flap necrosis and the subsequent reduction in membrane exposure during a GBR procedure.

This prospective human study investigated the effect of the location of the initial crestal incision and subsequent flap survival at an early flap-healing phase. This study also proposed a clinical guideline for locating the avascular zone to assist in improved soft tissue wound healing during a GBR procedure.

\section{MATERIALS AND METHODS}

This study was part of a randomized controlled human study on the effect of GBR of implant-associated buccal dehiscence defects conducted from March of 2004 to June of 2005. All study participants read and signed an informed consent form. The use of human subjects in this study was reviewed and approved by the Health Science Institutional Review Board of the University of Michigan.

Twenty-nine submerged microtextured (MTX)surfaced implants were installed in 25 patients (12 females and 13 males) with horizontal ridge deficiency. Patients ranged in age from 28 to 71 years. All study participants were in good health, and only one patient was a current mild smoker. All sites were edentulous for $\geq 6$ months from the time of extraction.

Implant-associated buccal dehiscences were grafted with mineralized human allograft ${ }^{\ddagger}$ according to sandwich bone augmentation. ${ }^{22}$ Bovine collagen membrane ${ }^{\S}$ was used in 10 patients, whereas 10 sites

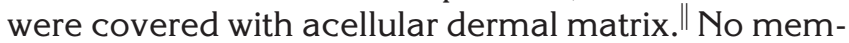
brane was used in nine patients. The width of the buccal keratinized gingiva (KG) of adjacent teeth was measured to determine whether it correlated with the length of the flap that survived. When gingival recession was present, measurement was made from the buccal cemento-enamel junction (CEJ) to the mucogingival junction (MGJ) to represent the KG width at the preextraction state (Fig. 1A). MGJ was identified using a rolling technique. Floss was used to measure the distance from the incision line to MGJ (Fig. 1B). For repeatable results, floss was tied
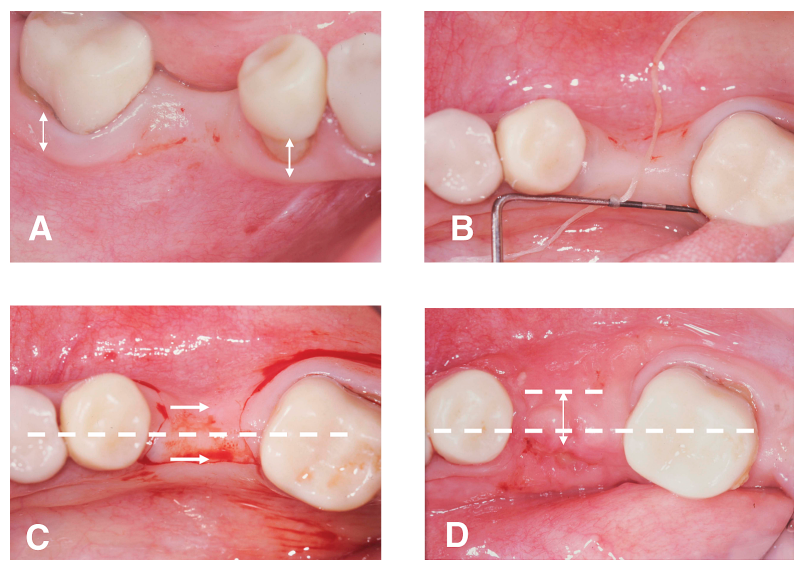

Figure I.

A) Arrows indicate the measurements for buccal keratinized gingiva of adjacent teeth. In the presence of gingival recession, the CEJ was used to represent $K G$ width of the preextraction state. B) Floss bisected the ridge to measure the incision location. The probe resting on the lingual CEJ of adjacent teeth was used for repeatable measurement. C) Arrows indicate the mucogingival junction and crestal incision. The dotted line represents the mid-crest. An incision was made 2 to $3 \mathrm{~mm}$ lingual to the mid-crest. D) Arrows indicate the flap that survived at 2 weeks.

to a probe resting on the lingual CEJ of adjacent teeth, and this bisected the edentulous ridge. An incision was made 2 to $3 \mathrm{~mm}$ lingual/palatal to the mid-crest (Fig. 1C). The incision position was measured from MGJ to the incision line. MGJ was reidentified at 2 weeks and 1 month to measure the amount of remaining keratinized gingiva, which represented the surviving portion of the buccal flap (Fig. 1D).

The term "vascular compensation" was used in this study to refer to a portion of the flap that survived beyond the mean KG width of adjacent teeth. The rationale was based upon clinical observations ${ }^{16,19,21}$ that the primary blood supply from the buccal flap may not extend beyond the length of the buccal flap at its preextraction state, even after complete wound healing. A mean width of buccal KG of adjacent teeth was used as a reference to estimate the length of the buccal flap at the preextraction state. We calculated this using the equation: vascular compensation $=$ mean $\mathrm{KG}$ of adjacent teeth minus length of flap that survived. A flap with a greater vascular compensation may indicate a greater collateral blood supply from underlying bone or an opposing flap.

To examine the effect of gingival thickness on the flap survival, gingival thickness was recorded at three locations using a caliper with 0.1-mm accuracy: midcrest and $6 \mathrm{~mm}$ apical to the buccal and lingual sides of the flap.

\footnotetext{
† Puros cortical/cancellous, Zimmer Dental, Carlsbad, CA. $\S$ BioMend Extend, Zimmer Dental.

\|| AlloDerm Regenerative Membrane, BioHorizons, Birmingham, AL.
} 
An independent samples $t$ test was performed for intragroup and intergroup comparisons between the exposed and non-exposed groups. Analysis of variance was used to compare the vascular compensation of the survived flap. The significance level was set at $P<0.05$.

\section{RESULTS}

Table 1 shows that the baseline incision locations from MGJ in three groups were similar, with no significant difference $(P=0.444)$. The mean keratinized gingiva of the adjacent teeth also was similar without significant difference $(P=0.815)$.

The mean keratinized tissue width of the buccal flap at 2 weeks in bovine collagen membrane and acellular dermal matrix groups was $3.3 \pm 1.1 \mathrm{~mm}$ and $3.5 \pm$ $1.5 \mathrm{~mm}$, respectively. The difference between the mean KG width of the survived buccal flap at 2 weeks and that of adjacent teeth, as represented by "vascular compensation," was $0.1 \pm 0.6 \mathrm{~mm}$ and $0.4 \pm 0.9 \mathrm{~mm}$ for the two membrane groups. Conversely, the control group had a mean vascular compensation of $1.6 \pm 1.1$ $\mathrm{mm}$. An intergroup comparison of these differences was statistically significant (Fig. 2).

Gingival thickness, measured at mid-crest and $6 \mathrm{~mm}$ buccal and lingual of the mid-crest, was compared between patients with early membrane/implant exposure and non-exposure (Fig. 3). Ten cases of early membrane exposure occurred at 2 weeks, whereas 19 patients showed complete closure at 2 weeks. When comparing the gingival thickness at exposed and non-exposed sites, only the palatal/lingual thickness showed a significant difference $(P=$ 0.002 ). The mean palatal/lingual gingival thickness of non-exposed cases was $3.0 \mathrm{~mm}$, whereas that of exposed cases was $1.1 \mathrm{~mm}$.

\section{DISCUSSION}

The aim of this study was to address prospectively how the position of the crestal incision over the GBR site may influence flap survival and associated membrane exposure. The hypothesis was based upon the fact that the primary blood supply of buccal and lingual/palatal gingival tissue at the preextraction state extends up to the gingival margin. Upon extraction, the area where the buccal and lingual flaps meet heals with a 1-to 2-mm zone of discontinuity of the vascular anastomoses, as observed in a human cadaver study. ${ }^{19}$ As shown in animal and human studies, ${ }^{14,17}$ reduced edema, flap necrosis, and/or discomfort that is associated with incisions made at or near this zone suggest further that primary vessels may not cross over this zone.

In our study, incisions were made 2 to $3 \mathrm{~mm}$ lingual/palatal to the mid-crest as a part of the surgical protocol. All incisions were placed within keratinized gingiva. However, some patients experienced more flap necrosis than others. This suggests that the location of the "avascular zone" that was observed by Kleinheinz et al. ${ }^{19}$ may have changed as the edentulous ridge underwent horizontal resorption. Midcrest, in an edentulous ridge without much horizontal resorption, may serve as a good estimator for this zone, as seen in Scharf and Tarnow's study. ${ }^{14}$ However, in a significantly reduced ridge, the midcrest may not estimate the location of the avascular zone.

It was speculated that a paracrestal incision may leave a portion of flap that is unsupported by a primary vascular supply from the buccal or lingual flap. Survival of this portion of the flap depends upon a collateral blood supply, acting like a free gingival graft. ${ }^{14}$ Collateral blood supplies may come from

\section{Table I.}

\section{Comparison of Clinical Measurements}

\begin{tabular}{|c|c|c|c|c|c|c|c|}
\hline & N & $\begin{array}{l}\text { Mean Age } \\
\text { (years) }\end{array}$ & $\begin{array}{c}\text { Mean Incision } \\
\text { Location } \pm \mathrm{SD}(\mathrm{mm})\end{array}$ & $\begin{array}{c}\text { Mean KG of } \\
\text { Adjacent Teeth } \\
\pm \mathrm{SD}(\mathrm{mm})\end{array}$ & $\begin{array}{c}\text { Mean Buccal KG } \\
\text { of Survived Flap at } 2 \\
\text { Weeks } \pm \text { SD }(\mathrm{mm})\end{array}$ & $\begin{array}{l}\text { Mean Difference Between } \\
\text { Mean KG of Adjacent } \\
\text { Teeth Minus Mean Buccal } \\
\text { KG at } 2 \text { Weeks } \pm \text { SD (mm) }\end{array}$ & $P$ Value* \\
\hline ADM & 10 & 48 (range, 28-66) & $5.0 \pm 1.6$ & $3.2 \pm 1.0$ & $3.3 \pm 1.1$ & \multirow{2}{*}[\begin{array}{l}{0.4\pm0.9}\\
{1.6\pm1.1}\end{array}]{+} & 0.613 \\
\hline BME & 10 & 52 (range, 28-66) & $4.3 \pm 1.8$ & $3.1 \pm 1.0$ & $3.5 \pm 1.5$ & & 0.264 \\
\hline$P$ value & - & - & 0.444 & 0.815 & - & 0.002 & \\
\hline
\end{tabular}

$\mathrm{ADM}=$ AlloDerm Regenerative Membrane; $\mathrm{BME}=$ BioMend Extend; $-=$ not applicable.

Values in bold are statistically significant.

* P value from the paired samples $t$ test comparing the width of KG of adjacent teeth and length of flap survived in each group. Statistical significance was set at $P<0.05$.

$\dagger$ Pairwise Bonferroni correction for multiple comparison showing statistical significance at $P<0.05$

† The control group used mineralized human allograft (Puros). 


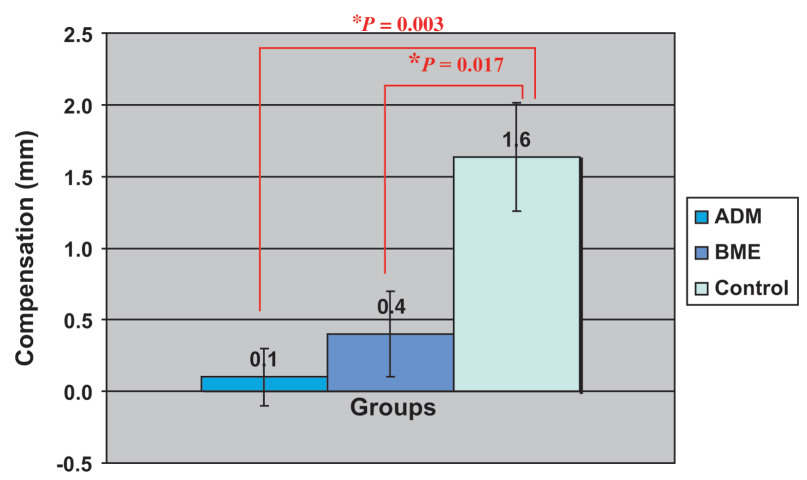

Figure 2.

Values are recorded as mean \pm SE. Statistical significance was set at $P<0.05$. The control group used mineralized human allograft (Puros) without a membrane. ADM = AlloDerm Regenerative Membrane; $B M E=$ BioMend Extend.

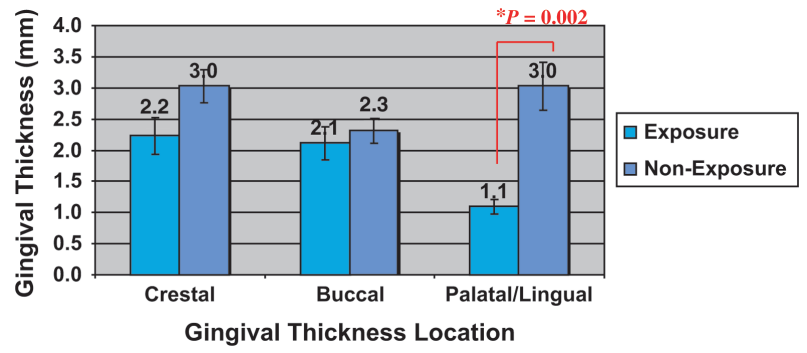

Figure 3.

Values are recorded as mean \pm SE. Statistical significance was set at $P<0.05$. Gingival thickness was measured at mid-crest and $6 \mathrm{~mm}$ buccal and palatalllingual to mid-crest.

underlying bone and opposing flap. However, in the presence of a membrane, the unsupported portion of the flap loses its main collateral blood supply from the underlying bone; it may experience flap necrosis, and, subsequently, an increased risk for membrane exposure after a regenerative procedure. We observed that the mean width of keratinized gingiva of adjacent teeth closely estimated the length of the surviving buccal flap in membrane groups. The surviving flap likely represents the keratinized width of the preextraction state, with the primary blood supply intact. Conversely, in the control group, in which we did not use a membrane, a significantly greater portion of the buccal flap survived beyond our estimator of the mean width of buccal KG of adjacent teeth. We introduce a term, "vascular compensation," to represent this portion. This term is used in this study to describe our clinical observation. It is our speculation that, in the absence of membrane, collateral blood supply from underlying bone may remain uninterrupted and lead to a greater vascular compensation.
We also compared the gingival thickness between membrane-exposed and non-exposed cases. Midcrestal or buccal gingival thickness did not have any significant impact on the occurrence of membrane exposure. However, the palatal/lingual gingival thickness showed a significant difference between these two groups. The mean palatal/lingual gingival thickness was $3.0 \mathrm{~mm}$ in non-exposed cases compared to $1.1 \mathrm{~mm}$ in exposed cases. The thickness of the palatal/lingual flap, in addition to the underlying bone, may serve as a source of collateral blood supply to the unsupported portion of the opposing flap. Therefore, thick gingiva at the incision site may provide more surface area for reestablishing the blood supply to this unsupported portion of the flap.

Studies with a larger sample size and more histologic investigations are needed to confirm our finding. However, the clinical implications made in our study are multifold. In addition to many factors described for GBR success, one can change the incision location to maintain a continuous vascular supply to an unsupported part of the mobilized flap. In turn, this may minimize flap necrosis and further reduce the risk for membrane exposure. In a ridge with significant horizontal ridge resorption, the mean keratinized width of adjacent teeth might be useful for locating the zone of avascularity. However, for an incision that is made in thick gingiva $(\geq 3.0 \mathrm{~mm}$ ), which is encountered most commonly in maxillary edentulous ridge, its position may not be as critical as one made in thin gingiva (i.e., mandibular edentulous ridge) because thick gingiva provide a greater surface area for collateral blood supply.

\section{ACKNOWLEDGMENT}

This work was supported, in part, by the University of Michigan Periodontal Graduate Student Research Fund.

\section{REFERENCES}

1. Cesar-Neto JB, Benatti BB, Sallum EA, Nociti FH Jr. Bone density around titanium implants may benefit from smoking cessation: A histologic study in rats. Int J Oral Maxillofac Implants 2005;20:713-719.

2. Saldanha JB, Pimentel SP, Casati MZ, et al. Guided bone regeneration may be negatively influenced by nicotine administration: A histologic study in dogs. J Periodontol 2004;75:565-571.

3. Majzoub Z, Berengo M, Giardino R, Aldini NN, Cordioli $\mathrm{G}$. Role of intramarrow penetration in osseous repair: A pilot study in the rabbit calvaria. J Periodontol 1999; 70:1501-1510.

4. Gelb DA. Immediate implant surgery: Three-year retrospective evaluation of 50 consecutive cases. Int $J$ Oral Maxillofac Implants 1993;8:388-399.

5. Zitzmann NU, Naef R, Scharer P. Resorbable versus nonresorbable membranes in combination with 
Bio-Oss for guided bone regeneration. Int $J$ Oral Maxillofac Implants 1997;12:844-852.

6. Zitzmann NU, Scharer P, Marinello CP. Factors influencing the success of GBR. Smoking, timing of implant placement, implant location, bone quality and provisional restoration. J Clin Periodontol 1999; 26:673-682.

7. Carpio L, Loza J, Lynch S, Genco R. Guided bone regeneration around endosseous implants with anorganic bovine bone mineral. A randomized controlled trial comparing bioabsorbable versus non-resorbable barriers. J Periodontol 2000;71:1743-1749.

8. Vanden Bogaerde L. A proposal for the classification of bony defects adjacent to dental implants. Int $J$ Periodontics Restorative Dent 2004;24:264-271.

9. Palmer RM, Floyd PD, Palmer PJ, Smith BJ, Johansson $\mathrm{CB}$, Albrektsson T. Healing of implant dehiscence defects with and without expanded polytetrafluoroethylene membranes: A controlled clinical and histological study. Clin Oral Implants Res 1994;5:98-104.

10. Jovanovic SA, Spiekermann H, Richter EJ. Bone regeneration around titanium dental implants in dehisced defect sites: A clinical study. Int J Oral Maxillofac Implants 1992; 7:233-245.

11. Lekholm U, Becker W, Dahlin C, Becker B, Donath K, Morrison E. The role of early versus late removal of GTAM membranes on bone formation at oral implants placed into immediate extraction sockets. An experimental study in dogs. Clin Oral Implants Res 1993;4: $121-129$.

12. Nowzari H, Slots J. Microbiologic and clinical study of polytetrafluoroethylene membranes for guided bone regeneration around implants. Int $J$ Oral Maxillofac Implants 1995;10:67-73.

13. Machtei EE. The effect of membrane exposure on the outcome of regenerative procedures in humans: A meta-analysis. J Periodontol 2001;72:512-516.

14. Scharf DR, Tarnow DP. The effect of crestal versus mucobuccal incisions on the success rate of implant osseointegration. Int J Oral Maxillofac Implants 1993; 8:187-190.

15. Hunt BW, Sandifer JB, Assad DA, Gher ME. Effect of flap design on healing and osseointegration of dental implants. Int J Periodontics Restorative Dent 1996; 16:582-593.

16. Cranin AN, Klein M, Sirakian A, Russel D, Lee CJ. Effects of incision design on endosteal implant host sites. J Dent Res 1991;70(Spec. Issue):279(Abstr. 109).

17. Cranin AN, Sirakian A, Russell D, Klein $M$. The role of incision design and location in the healing processes of alveolar ridges and implant host sites. Int $J$ Oral Maxillofac Implants 1998;13:483-491.

18. Langer B, Langer L. The overlapped flap: A surgical modification for implant fixture installation. Int J Periodontics Restorative Dent 1990;10:208-215.

19. Kleinheinz J, Buchter A, Kruse-Losler B, Weingart D, Joos U. Incision design in implant dentistry based on vascularization of the mucosa. Clin Oral Implants Res 2005; 16:518-523.

20. Heydenrijk K, Raghoebar GM, Batenburg RH, Stegenga B. A comparison of labial and crestal incisions for the 1 -stage placement of IMZ implants: A pilot study. J Oral Maxillofac Surg 2000;58:1119-1123.

21. Casino AJ, Harrison P, Tarnow DP, Morris HF, Ochi S. The influence of type of incision on the success rate of implant integration at stage II uncovering surgery. J Oral Maxillofac Surg 1997;55:31-37.

22. Wang H-L, Misch C, Neiva RF. Sandwich bone augmentation technique: Rationale and report of pilot cases. Int J Periodontics Restorative Dent 2004;24: 232-245.

Correspondence: Dr. Hom-Lay Wang, Department of Periodontics and Oral Medicine, School of Dentistry, University of Michigan, 1011 N. University Ave., Ann Arbor, MI 481091078. Fax: 734/936-0374; e-mail: homlay@umich.edu.

Accepted for publication August 7, 2006. 